\title{
Full-Scale Testing of a Reinforced Concrete Frame under Fire
}

\author{
Ji Yeon Kang, Hyun Ah Yoon, Eun Mi Ryu, Hee Sun Kim, Yeong Soo Shin
}

\begin{abstract}
Most experimental studies have been performed to investigate the fire resistance of a single member, beam, column, wall, and slab. However, a limited number of experimental studies have been performed on full-scale structures, especially reinforced concrete (RC) structures. This paper aims at investigating temperature distribution on a full-scale $\mathrm{RC}$ structure under fire. RC structure is constructed 2,400 (width) $\times$ 1,000 (length) $\times 2,100$ (height) $\mathrm{mm}$ and consists of one column, two beams, two walls, and two slabs. This specimen is heated on one side with ISO-834 standard time-temperature curve for 2 hours and temperature distributions during the test are measured using thermocouples inside the structure. To investigate the relationship of temperature distributions between full-scale structure and a single member, the experimental results of full-scale structure are compared with those of a single member throughout the other experimental studies.
\end{abstract}

Keywords - Fire, Full-scale testing, Normal strength concrete, Reinforced concrete frame, Temperature distribution

\section{Introduction}

Most studies have been carried out to investigate the fire resistance of each reinforced concrete member, beam, column, wall, and slab. The structural response of a structure in fire is more complicated than that of a single member, but it isn't easy to perform fire test of a structure. Therefore, the fire design of a structure should be approached based on the temperature achieved by each member's fire testing.

There are a few experimental studies of full-scale steel and composite structures [1]-[2]. Only two of these have been performed reinforced concrete frame to investigate the fire response and post-fire seismic performance [3]-[4]. P. Kamath et al. [3] perform experiments for structural behavior of 5story reinforced concrete building under earthquake and fire. This paper reports the residual capacity of a RC frame by three phase testing procedure ; gravity loading, simulated earthquake loading, and fire. J. Xiao et al. [4] perform the fire and the post-fire seismic tests on single-span and single-story frames. This paper is compared between post-fire seismic

Ji Yeon Kang, Hyun Ah Yoon, Eun Mi Ryu, Hee Sun Kim

The department of architectural engineering / Ewha Womans University Korea

Yeong Soo Shin

The department of architectural engineering / Ewha Womans University Korea frames and one fire-unexposed frame.

It is necessary to perform some testing on a full-scale structure to approach more accurate evaluation of structure behaviors. The objective of this paper is to investigate the thermal behavior of reinforced concrete structure under fire. In addition, the relationships of experimental results between full-scale structure and single members are investigated in comparison with the other experimental studies of single members.

\section{Experimental Approach}

\section{A. Fabrication of Test Specimen}

A single story reinforced concrete frame is constructed 2,400 (width) $\times 1,000$ (length) $\times 2,100$ (height) $\mathrm{mm}$ as shown in Fig. 1. The height of the frame is determined to consider the size of furnace, but the size of each member is designed for the actual size. The test specimen consists of one column, two beams, two walls, and two slabs : The column size is 350 (width) $\times 350$ (depth) $\times 1,800$ (height) $\mathrm{mm}$, the walls sizes are 2,400 (length) $\times 1,800$ (height) $\times 150$ (thickness) $\mathrm{mm}$ and 850 (length) $\times 1,800$ (height) $\times 150$ (thickness) $\mathrm{mm}$, the beam sizes are 200 (width) $\times 300$ (depth) $\times 1,900$ (length) $\mathrm{mm}$ and 200 (width) $\times 300$ (depth) $\times 500$ (length) $\mathrm{mm}$, and the slab size is 2,400 (width) $\times 1,000$ (length) $\times 150$ (thickness) $\mathrm{mm}$ as shown in Fig. 2. The specimen is designed in accordance with Korean Concrete Institute (KCI) design recommendations.

TABLE I. MIX PROPORTION FOR CONCRETE

\begin{tabular}{ccccccccc}
\hline \multirow{2}{*}{$\begin{array}{c}28 \text { days' compressive } \\
\text { strength }\end{array}$} & $\begin{array}{c}\text { W/C } \\
(\boldsymbol{\%})\end{array}$ & $\begin{array}{c}\text { s/a } \\
(\boldsymbol{\%})\end{array}$ & \multicolumn{4}{c}{ Weight per unit volume $\left(\mathbf{k g} / \mathbf{m}^{\mathbf{3}}\right)$} \\
\hline $26.08 \mathrm{MPa}$ & 51.2 & 49.8 & 162 & $\boldsymbol{C}$ & $\boldsymbol{S}$ & $\boldsymbol{G}$ & $\boldsymbol{A D}$ \\
\hline
\end{tabular}

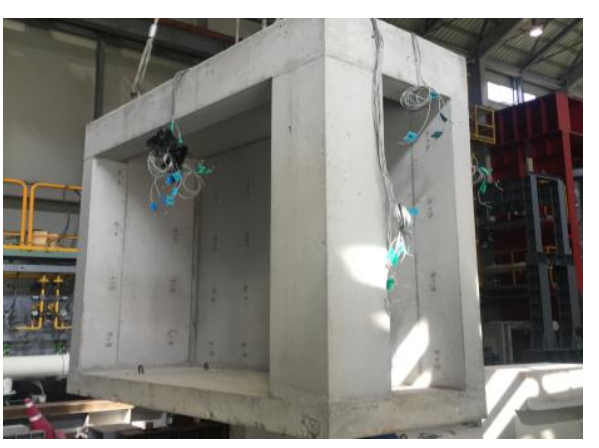

Figure 1. Test specimen 


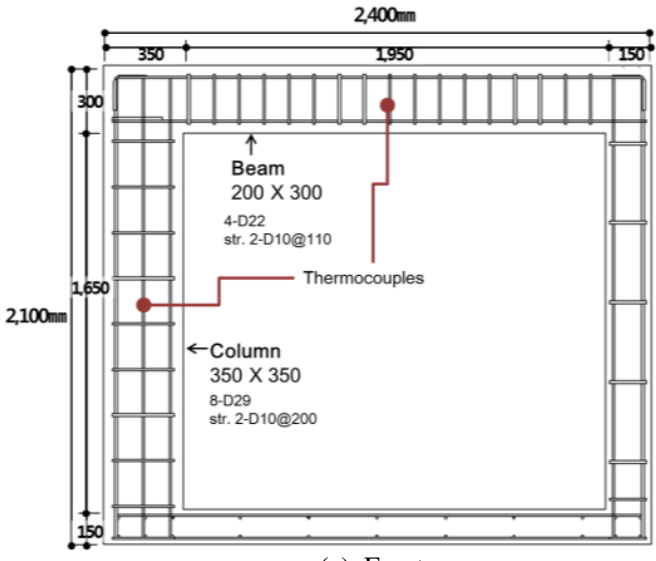

(a) Front

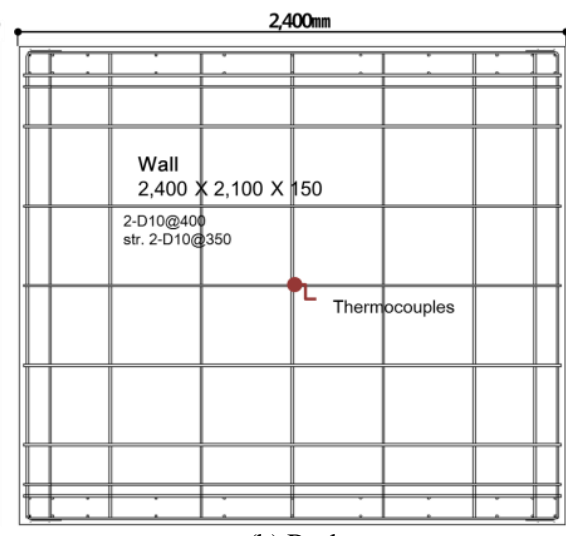

(b) Back

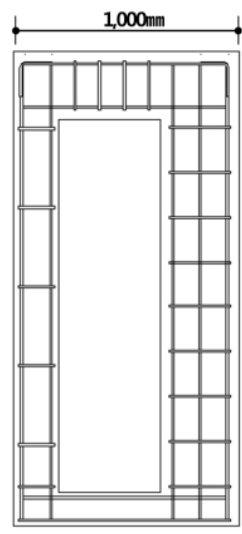

(c) Left

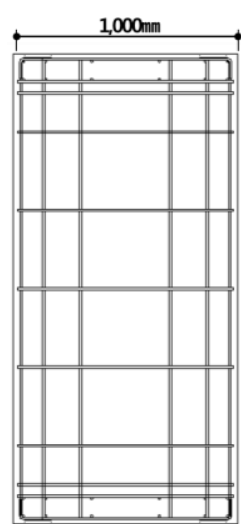

(d) Right

Figure 2. Deminsions of test specimen

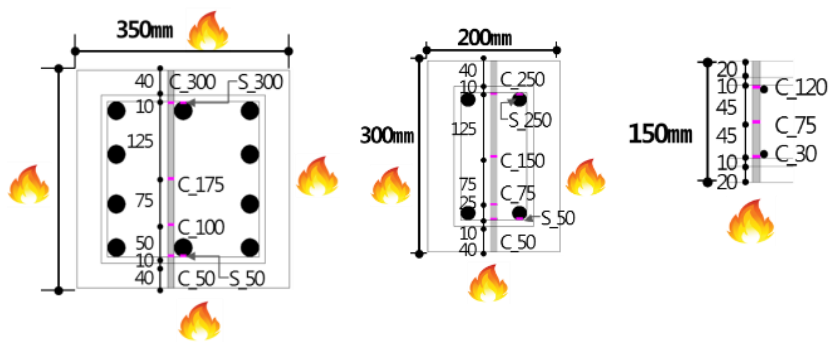

Figure 3. Thermocouples location (left:column, middle:beam, right:wall)

The thermocouples are palced in the mid-point on each column, beam, and wall. Figure 3 shows the details of the member sections and theocouples locations. The temperatures in the column and beam section are measured by six thermocouples placed in each member. In the case of column, four themocouples are placed in $50 \mathrm{~mm}, 100 \mathrm{~mm}, 175 \mathrm{~mm}$, and $300 \mathrm{~mm}$ from the surface exposed to fire and two themocouples are placed in reinforcing bars. In the beam, four themocouples are placed in $50 \mathrm{~mm}, 75 \mathrm{~mm}, 150 \mathrm{~mm}$, and $250 \mathrm{~mm}$ from the surface exposed to fire and two themocouples are placed in reinforcing bars. Lastly, three themocoouples are installed at the wall. The temperatures are

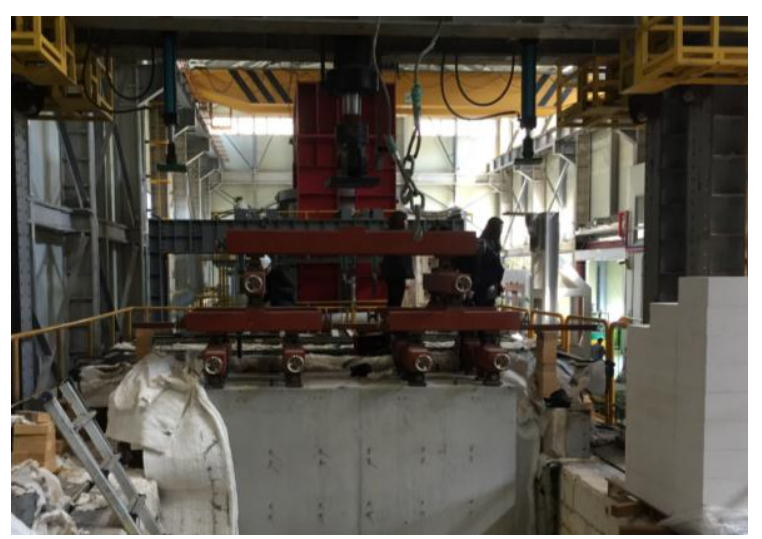

Figure 4. Specimen in a furnace measured $30 \mathrm{~mm}, 75 \mathrm{~mm}$, and $120 \mathrm{~mm}$ from the surface exposed to fire.

The mix proportion for the concrete is presented in Table 1 . The specimen is cured for five months at room temperature and the 28-day compressive strength is measured $26 \mathrm{MPa}$ from the material tests. The yield strength and elastic modulus of reinforcing steel bars are $439 \mathrm{MPa}$ and $156 \mathrm{MPa}$, respectively.

\section{B. Fire Test Set-Up and Procedure}

The specimen is initially loaded under uniform loading with constant loads before high temperature is applied. The initial loads are assumed as dead load $+0.4 \times$ live load, that is $552 \mathrm{kN}$. The test setup for the specimen in a furnace is shown in Fig. 4.

The test temperature is controlled by ISO 834 standard fire curve, which is shown in Fig. 5. To simulate a compartment fire, the only front face of specimen is heated for 2 hours. That is, all four faces of column are exposed to fire, while three faces of beam and one face of wall are exposed to fire.

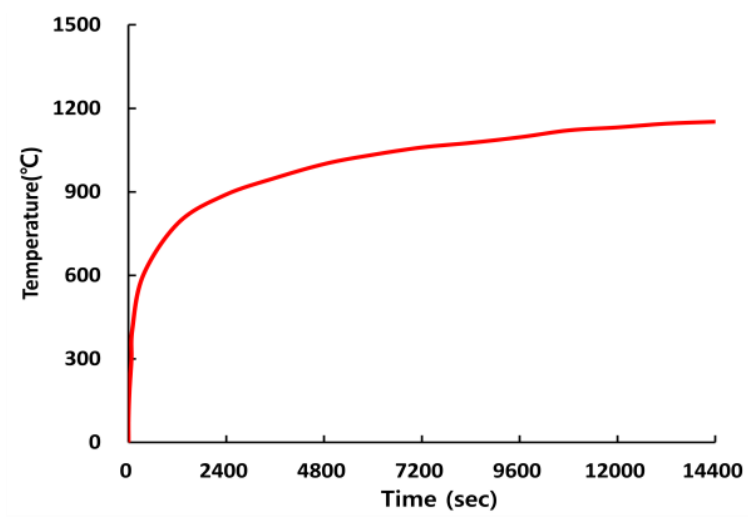

Figure 5. ISO-834 standard time-temperature curve 


\section{Experimental Results}

Figure 6 8 illustrate the time-temperature curves of the members of the specimen during 2 hours of heating. At C_30 in the wall, the temperature increases rapidly until $120 \mathrm{~min}$. of heating as shown in Fig. 6. However, the temperatures at $\mathrm{C}_{-} 75$ and $C_{-} 120$ are much lower than the temperature at $C_{-} 30$. The temperatures at C_30, C_75, and C_120 reach $638.8^{\circ} \mathrm{C}$, $212.7^{\circ} \mathrm{C}$, and $106.6^{\circ} \mathrm{C}$, respectively.

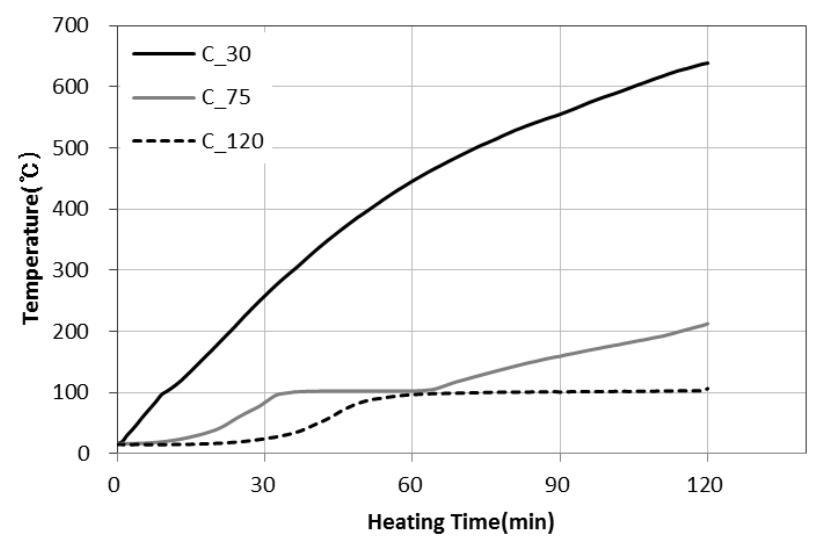

Figure 6. Time-temperature relationship of the wall

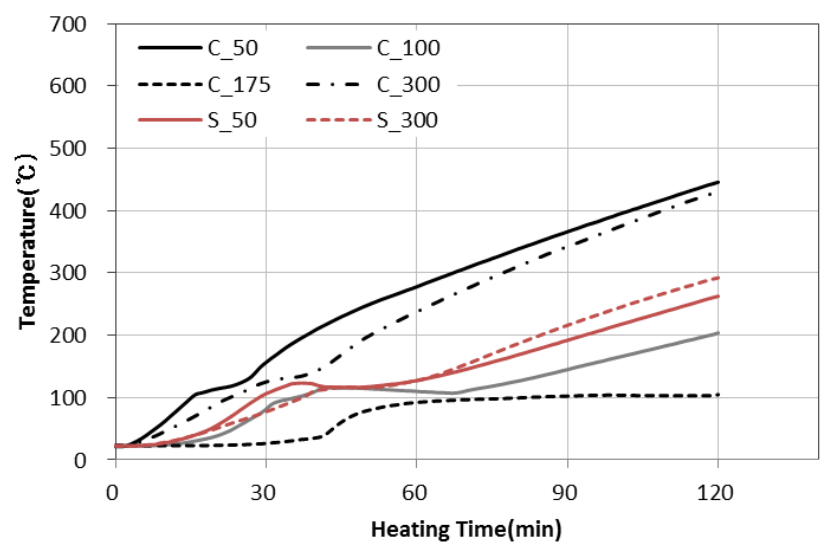

Figure 7. Time-temperature relationship of the column

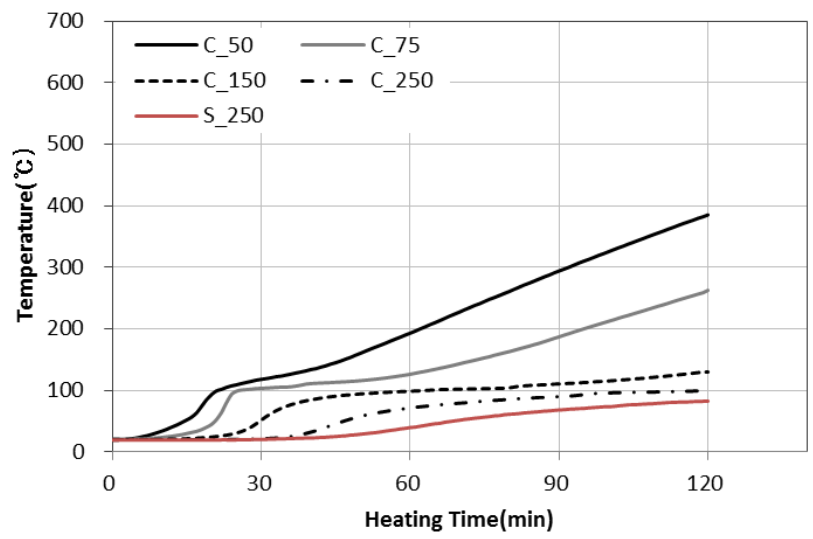

Figure 8. Time-temperature relationship of the beam
Figure 7 represents the temperature distribution results from the fire test in the column. The temperatures at C_50 and C_300 are $445.7^{\circ} \mathrm{C}$ and $431.5^{\circ} \mathrm{C}$, respectively because C_50 and C_300 are placed at same distance from the surface exposed to fire. At the same locations, the temperatures in concrete are higher than those in reinforcing bars. The temperature at C_50 in beam is $385.4^{\circ} \mathrm{C}$ and higher than other locations as shown in Figure 8. But, the temperature at C_50 in beam is lower than that in column even though the distance from the surface exposed to fire is same. Because all four faces of the column is exposed to fire while three faces of the beam is exposed to fire.

\section{Iv. Comparison of other experimental results}

To investigate the relationship of the temperature distribution between full-scale structure and single members, the experimental studies are selected on the condition of the similar member size and material properties as this test specimen

\section{A. Wall}

H. Yoon et al. [5] perform the fire test of RC walls on one side exposed to fire. The wall size is 750 (length) $\times 1,300$ (height) $\times 150$ (thickness) $\mathrm{mm}$ as shown in Fig. 9. The compressive strength of the concrete is $26 \mathrm{MPa}$ and the specimen is tested under $260 \mathrm{kN}$ loading at elevated temperature in furnace. After 2 hours of heating, the temperature measured at distance of $30 \mathrm{~mm}$ from the surface exposed to fire is $616.1^{\circ} \mathrm{C}$ while the wall in full-scale specimen is $638.8^{\circ} \mathrm{C}$. However, the temperatures at $75 \mathrm{~mm}$ and $120 \mathrm{~mm}$ distance from the surface exposed to fire are $291.5^{\circ} \mathrm{C}$ and $170.3^{\circ} \mathrm{C}$, respectively while the wall in full-scale specimen are $212.7^{\circ} \mathrm{C}$ and $106.6^{\circ} \mathrm{C}$, respectively. Therefore the temperature at $30 \mathrm{~mm}$ distance from the surface exposed to fire in a wall specimen is similar to full-scale specimen, but there are a little difference between those in $75 \mathrm{~mm}$ and $120 \mathrm{~mm}$ distances.

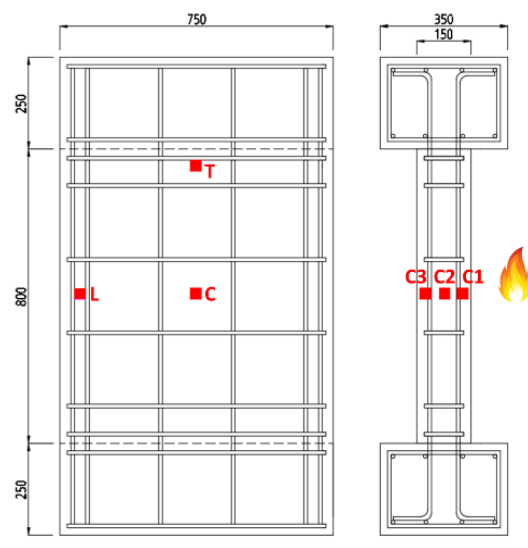

Figure 9. Details of a wall specimen 


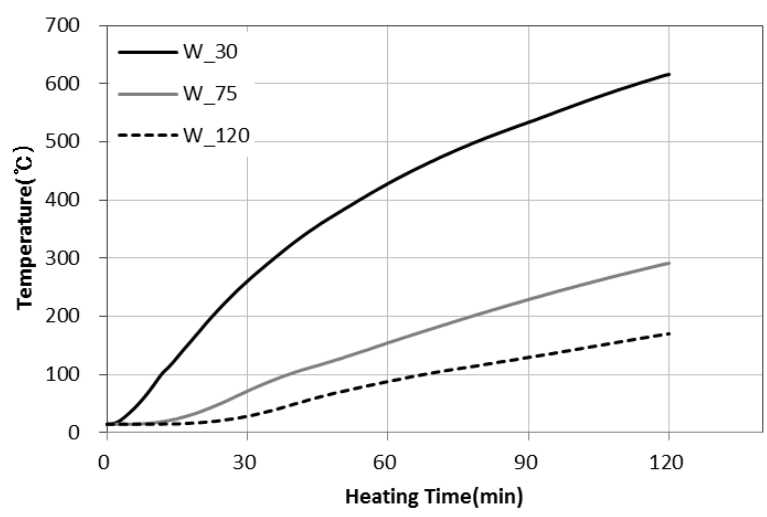

Figure 10. Time-temperature relationship of the wall specimen

\section{B. Column}

S. Lee et al. [6] perform the fire test of RC column on allsides exposed to fire. The size of a column is 350 (width) $\times$ 350 (depth) $\times 3,360$ (length) $\mathrm{mm}$ as shown in Fig. 11. The compressive strength of the concrete is $24.5 \mathrm{MPa}$ and the specimen is tested under $637.4 \mathrm{kN}$ of concentric loads at elevated temperature in furnace. After 2 hours of heating, the temperature measured at distance of cover thickness $55 \mathrm{~mm}$ is $310^{\circ} \mathrm{C}$ while the column in full-scale specimen is $445.7^{\circ} \mathrm{C}$. However, the temperature at the center of section is $116.7^{\circ} \mathrm{C}$ while the column in full-scale specimen is $104.8^{\circ} \mathrm{C}$. There is a difference between the temperature at cover thickness in a column specimen and that in full-scale specimen because the column specimen is loaded about three times larger than the column in full-scale specimen under fire.

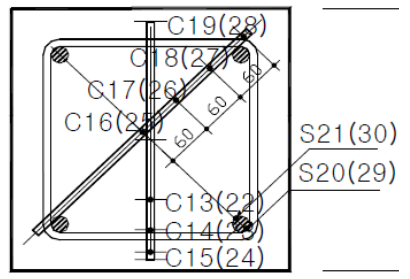

Figure 11. Location of thermocouples in column specimen

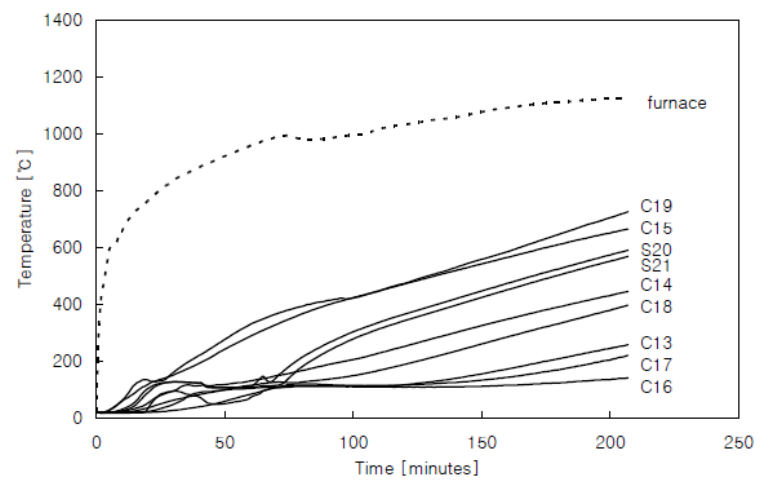

Figure 12. Temperature-time relationship of the column specimen

\section{Beam}

S. Lee et al. [7] carry out the fire test of RC beam on three sides exposed to fire. The beam size is 250 (width) $\times 400$ (depth) $\times 4,700$ (length) $\mathrm{mm}$ as shown in Fig. 13. The compressive strength of the concrete is $21.4 \mathrm{MPa}$ and the specimen is tested under four point $86.3 \mathrm{kN}$ loading at elevated temperature in furnace. After 2 hours of heating, the temperature measured at distance of cover thickness $50 \mathrm{~mm}$ is $356^{\circ} \mathrm{C}$ while the beam in full-scale specimen is $385.4^{\circ} \mathrm{C}$. However, the temperatures at the center of section is $155.3^{\circ} \mathrm{C}$ while the beam in full-scale specimen is $100.4{ }^{\circ} \mathrm{C}$.

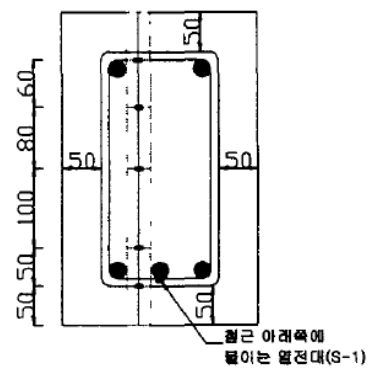

Figure 13. Location of thermocouples in column specimen

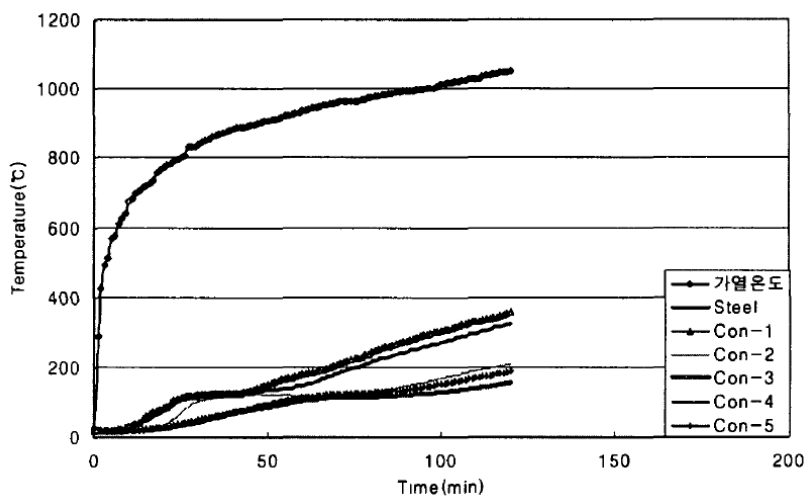

Figure 14. Time-temperature relationship of the beam specimen

\section{v. Conclusion}

This study reports thermal behavior on one single reinforced concrete frame under fire. The following conclusions can be drawn:

1) This paper is shown that the experimental results of single member under similar conditions to actual structure are in good agreement with those of full-scale structure.

2) The temperature distribution in a member differs as the size of members, the magnitude of the initial load under fire and so on. Additional investigations to these factors are required to have an effect on thermal behaviors of the members. 


\section{Acknowledgment}

This work was supported by the National Research Foundation of Korea (NRF) grant funded by the Korea government (MEST) (No. NRF-2013R1A2A2A01015603).

\section{References}

[1] S. Foster, M.chladana, C. Hsieh, I. Burgess, and R. Plank, "Thermal and structural behaviour of a full-scale composite building subject to a severe compartmen fire", Fire Safety Journal, vol. 42, pp183-199, 2007

[2] Y. Dong, E. Zhu, and K. Prasad, "Thermal and structural response of two-storey two-bay composite steel frames under furnace loading", Fire Safety Journal, vol. 44, pp439-450, 2009

[3] P. Kamath, U. Sharma, V. Kumar, P. Bhargava, A. Usmani, B. Singh, Y. Singh, J. Torero, M. Gillie, and P. Pankaj, "Full-scale fire test on an earthquake-damaged reinforced concrete frame.”, Fire Safety Journal, pp1-19, 2015

[4] J. Xiao, J. Li, and Z. Huang, 'Fire response of high-performance concrete frames and their post-fire seismic performance", ACI Structural Journal, pp531-540, 2008

[5] H.Yoon, J. Kang, H. Kim, and Y. Shin, "Investigation of fire damaged reinforced concrete walls with axial force", $18^{\text {th }}$ International Conference on Civil Engineering and Building Materials, 2016

[6] S. Lee, "Fire-damaged structural behavior of normal strength reinforced concrete columns in full scale", Master's degree, Chung-Ang University, 2003

[7] S. Lee, "A study on structural behaviors of fire-demaged reinforced concrete beams with normal strength concrete, Master's degree, Ewha Womans University, 2003

About Author (s):

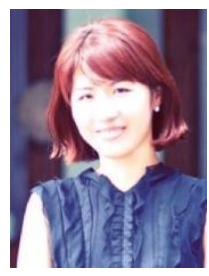

Ji Yeon Kang was born in Busan, South Korea, May 23, 1978. She is with the Architectural Engineering Department, Ewha Womans University, Seoul, South Korea.

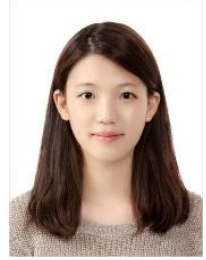

Hyun Ah Yoon was born in Suncheon, South Korea, October 23, 1992. She is with the Architectural Engineering Department, Ewha Womans University, Seoul, South Korea.

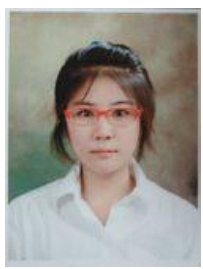

Eun Mi Ryu was born in Daegu, South Korea, April 30, 1990. She is with the Architectural Engineering Department, Ewha Womans University, Seoul, South Korea.

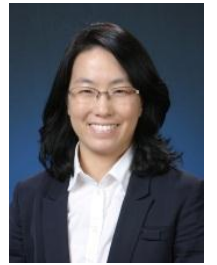

Hee Sun Kim was born in Seoul, South Korea, December 26, 1979. She is PROFESSOR in Ewha Womans University, Seoul, South Korea. Prof. Kim is with the Architectural Engineering Department, Ewha Womans University, Seoul, South Korea.

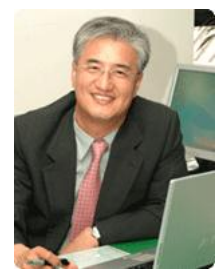

Yeong Soo Shin was born in Busan, South Korea, May 10, 1956. He is PROFESSOR in Ewha Womans University, Seoul, South Korea. Prof. Shin is with the Architectural Engineering Department, Ewha Womans University, Seoul, South Korea. 